

\section{CAMINHOS PARA DESENVOLVER SOFTWARE}

| POR CLÁUDIO LARIEIRA

\section{A transformação digital exige a aceleração de projetos para o desenvolvimento de aplicações de maneira mais ágil, rápida e com maior valor. Como enfrentar esse desafio?}

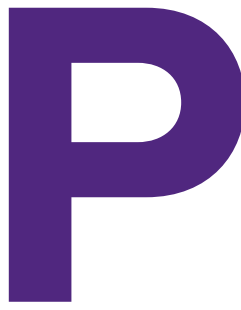

or conta da Covid-19, muitas organizações precisaram de um dia para o outro estabelecer novos modelos de operação. A transformação digital acelerou-se. Foi necessário realizar um esforço mais intenso em criar, manter e melhorar as soluções de negócio utilizando novas tecnologias. Essa mudança trouxe novas demandas e desafios ao desenvolvimento de software. Como enfrentá-los?

\section{CENÁRIO ATUAL}

Em 2020, realizamos uma pesquisa com profissionais de mercado perguntando sobre as tecnologias digitais que foram adotadas ou alavancadas no Brasil durante a pandemia da Covid-19. Inteligência artificial, blockchain e mobile foram as mais citadas. No futuro pós-pandemia, os entrevistados acreditam que inteligência artificial, realidade aumentada, robotização de processos e data analytics serão, nessa ordem, as mais promissoras. Como todas essas tecnologias dependem de programação para operação e gestão, será necessário produzir software com qualidade e de maneira mais rápida e barata.

No entanto, alcançar um novo padrão com agilidade não é tão fácil. Estudos recentes revelam as dificuldades que as organizações têm enfrentado atualmente ao desenvolver seus softwares, como: surgimento constante de novas tecnologias, aplicações, plataformas digitais e ecossistemas; falta de conhecimento aprofundado sobre as tecnologias emergentes; carência de profissionais capacitados; falta de integração entre os times de projeto distribuídos em locais e tempos diferentes; instabilidade dos cenários políticos, econômicos e sociais, o que faz com que as organizações precisem mudar constantemente seus processos, tecnologias e estruturas para atender ao negócio; escassez de recursos financeiros, dados o alto custo de desenvolvimento e as recentes crises econômicas; complexidade na integração entre as plataformas digitais; e necessidade de automatizar o processo de desenvolvimento de software para ganhar produtividade.

Alguns dos desafios são velhos conhecidos das organizações e dos profissionais envolvidos com a produção de software. Mas, considerando a necessidade de se produzir software cada vez mais rápido, com menos recursos e para uma variedade maior de tecnologias, o desafio como um todo aumenta de forma exponencial.

\section{COMO SE PREPARAR PARA O FUTURO}

Mais do que apontar desafios, interessa-nos neste artigo apresentar sugestões de como efetivamente melhorar os projetos de desenvolvimento de software à luz do que a transformação digital potencialmente trará de impacto nos próximos anos. 


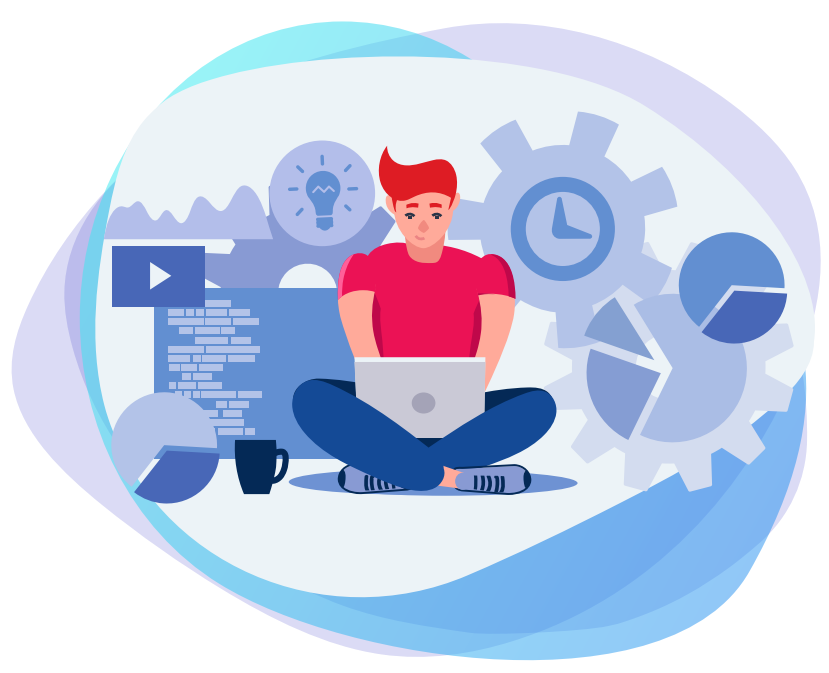

\section{Pessoas}

Comecemos refletindo sobre o mais fundamental, que é a necessidade de capacitar, com certa urgência, a mão de obra que tomará decisões, fará a gestão e implementará os softwares demandados para tecnologias digitais. É notório que as políticas e ações governamentais das últimas décadas não têm estado alinhadas para cumprir esse objetivo. Consequentemente, as ações de capacitação devem ser empreendidas pelas organizações que produzem software. Há diversos caminhos possíveis: formação técnica formal e extensa, treinamentos específicos, abordagem contínua de ensino-aprendizagem (como um lifelong learning), ou parcerias com universidades e centros de pesquisa.

Quanto mais desenvolvedores de software houver com conhecimento profundo sobre o negócio em que atuam, maior a chance de se desenvolverem soluções adequadas às necessidades das organizações. A criação e o desenvolvimento de times de projeto com alto grau de coesão, confiança, sinergia e colaboração podem ser fatores críticos de sucesso nesse objetivo de melhorar o desenvolvimento de software.

Esse entrosamento da equipe foi considerado um dos cinco fatores mais influentes na gestão do conhecimento em projetos de desenvolvimento de software, em pesquisa realizada por Ricardo Maciel Rodrigues para dissertação do Mestrado Profissional em Gestão para Competitividade, na linha de Tecnologia da Informação, da Escola de Administração de Empresas de São Paulo da Fundação Getulio Vargas (FGV EAESP), sob orientação do autor deste arti-
Os desafios de desenvolver softwares envolvem, por exemplo, a multiplicidade de novidades tecnológicas, a carência de profissionais, a falta de integração nos times, as mudanças organizacionais provocadas pela instabilidade no ambiente externo, a escassez de recursos financeiros e a complexidade na integração.

go. Os outros fatores que se destacaram foram qualidade dos relacionamentos interpessoais; capacidades e competências pessoais; características, percepções e motivações pessoais; e, principalmente, a percepção de que o conhecimento tem utilidade e deve circular entre todos, e não ficar restrito ao poder de um ou poucos indivíduos.

\section{Boas práticas}

Considerando que o desenvolvimento de software é um processo, vale destacar a importância de se estabelecer boas práticas para conduzir a tarefa de maneira que a organização crie o valor esperado ao mesmo tempo em que utiliza o melhor dos seus recursos. Para isso, muitas organizações têm migrado dos métodos tradicionais para os métodos ágeis. Mas, enquanto não finalizam suas jornadas de transição, devem se preparar de maneira mais adequada para conviver com essas duas realidades.

Passada uma primeira onda da adoção e do uso de métodos ágeis nas organizações, existe atualmente uma discussão latente e relevante em que se pondera que os métodos híbridos são a melhor opção, pois combinam o caminho mais inteligível dos métodos tradicionais ao mais focado nas necessidades dos clientes e na entrega de valor dos métodos ágeis. Nos métodos híbridos, é possível combinar o uso de cronogramas, planilhas de orçamento ou mapas de respostas a riscos (que são produtos de uma gestão de projetos mais tradicional) com o uso de quadros Kanban, ciclos de vida como Sprints ou papéis organizacionais como um Scrum Master (que são elementos típicos dos métodos 
ágeis), para criar um modelo de gerenciamento de projetos mais eficiente.

É importante ressaltar que o método de gestão do projeto deve ser compatível com o tipo de software que se pretende implementar, sob pena de se adotarem processos que "mais atrapalham do que ajudam". Supondo que uma organização decida implementar um novo aplicativo em um mobile, é sabido que os métodos ágeis são mais adequados, porque permitem o desenvolvimento em ciclos menores, com mais interação entre os desenvolvedores e com resultados tangíveis facilmente percebidos. Nesse caso, utilizar uma abordagem mais tradicional e engessada não seria recomendável. Já para softwares que tenham a necessidade de alto controle de escopo, de custos, de riscos, os métodos tradicionais são mais adequados, por oferecerem aos gestores um conjunto maior de ferramentas de planejamento e gestão dos projetos.

Não menos importante é garantir que o processo de desenvolvimento de software obtenha um grau de automação capaz de garantir boa produtividade, assim como integração entre os vários ambientes e arquiteturas em implementação, levando-se em conta também o custo-benefício. Essa automação refere-se principalmente à implantação de ferramentas capazes de criar software com base em especificações de alto nível que dispensem a codificação direta pelos desenvolvedores e que ajudem o time de desenvolvimento a controlar as versões dos softwares e os testes unitários e integrados de maneira automática e repetitiva - além de ferramentas que possibilitem uma integração mais facilitada entre os vários softwares.

O desenvolvimento de software baseado em plataformas digitais ou ecossistemas (conforme preconizado pelo Gartner Group e mais recentemente denominado de composable architecture) pode ser uma boa alternativa na produção de software, na medida em que se podem integrar soluções e aplicações sem ter de começar do zero. Ou seja, as organizações podem buscar "pedaços" de programas já prontos para criar assim uma aplicação que integre essas partes, economizando tempo e recursos no desenvolvimento de seus softwares.

\section{Alinhamento, parcerias e cultura}

A gestão dos projetos de desenvolvimento de software deve estar alinhada com a gestão da organização. Esse alinhamento implica minimamente três decisões pragmáticas: o gerenciamento conjunto e centralizado, para que haja ordenamento entre os vários projetos simultâneos em desenvolvimento (a chamada gestão de programas); a avaliação e

\section{Existe atualmente uma discussão} latente e relevante em que se pondera que os métodos híbridos são a melhor opção, pois combinam o caminho mais inteligível dos métodos tradicionais ao mais focado nas necessidades dos

$$
\begin{gathered}
\text { clientes e na entrega de valor dos } \\
\text { métodos ágeis. }
\end{gathered}
$$

seleção criteriosa dos projetos a serem desenvolvidos, para que se possa de fato trabalhar apenas nos melhores e assim não desperdiçar recursos; e a gestão da mudança provocada pelos projetos, para garantir que a operação da organização não seja prejudicada (considerando que os projetos um dia terminam e que seus produtos de software criados é que vão se tornar os novos processos e sistemas em uma organização).

Um caminho possível a ser trilhado por organizações que necessitam produzir software com maior desenvoltura é buscar a participação em consórcios ou comunidades de práticas. Por exemplo, existe já um grande volume de startups do grupo das tech (como Agrotech, Edutech, Fintech etc.) que podem impulsionar a produção de software especialista com base em suas experiências.

Por último, a institucionalização de uma cultura de experimentação, de inovação constante e de colaboração pode ajudar e muito no desafio de produzir software, pois alavanca a criatividade das pessoas e aumenta o potencial de criação dos times de projeto.

Implementar essas sugestões de maneira conjunta e integrada nos parece ser um bom caminho para melhorar os projetos de desenvolvimento de software e, assim, dar continuidade aos esforços de transformação digital estabelecidos nas organizações.

\footnotetext{
PARA SABER MAIS:

Júlia Mallmann. Com a escassez de talentos, empresas de tecnologia focam em capacitação, 2019. Disponivel em: bitly/gvexecutivocapacitacao Project Management Institute Rio Grade do Sul. Nova era da gestão de projetos terá métodos hibridos e agilidade, 2014. Disponivel em bit.ly/gvexecutivohibrido Kasey Panetta. Gartner keynote: the future of business is composable, 2020. Disponivel em:
}

CLÁUDIO LARIEIRA > Professor da FGV EAESP > claudio.larieira@fgv.br 